\title{
Valoración del Fondo de Aportaciones para la Infraestructura Social, en San Pedro Tlaquepaque, Jalisco
}

\section{Assessment of the Fondo de Aportaciones para la Infraestructura Social in San Pedro Tlaquepaque, Jalisco}

\author{
Alberto Arellano Ríos* (D) http://orcid.org/0000-0003-1227-4087 \\ Santos Joel Flores Ascencio ** (Dttp://orcid.org/0000-0001-6491-6446 \\ Roberto Iván Piedra Ascencio *** (1) http://orcid.org/0000-0003-0990-1123
}

\begin{abstract}
Resumen
En este artículo se analiza el Fondo de Aportaciones para la Infraestructura Social, en San Pedro Tlaquepaque, Jalisco, el cual dota de servicios básicos a la población más necesitada. Para ello se empleó un enfoque cualitativo, también se realizó una revisión exhaustiva de todos los documentos relacionados con el Fondo y seis entrevistas semiestructuradas a los funcionarios implicados en su implementación. Se concluye que el Fondo tiene partes positivas: productividad y obras ejercidas, satisfacción de los beneficiarios y eficiencia y reinversión de recursos; pero también están las negativas: deficiencias en la capacitación de los colaboradores, insuficiencia de materiales, canales de comunicación intermitentes, desconocimiento de la normatividad y falta de indicadores de medición. El aporte de este artículo es que se analiza una política sectorial y nacional, pero considerando la dimensión territorial, para comprender su implementación en un lugar específico, y así brindar mejores resultados para los beneficiarios.

Palabras clave: Fondo de Aportaciones para la Infraestructura Social; política pública; programas de bienestar social; marginación social; intervención estatal; gasto público; San Pedro Tlaquepaque.
\end{abstract}

\begin{abstract}
This article analyzes the Fondo de Aportaciones para la Infraestructura Social in San Pedro Tlaquepaque, Jalisco, which provides the neediest population with basic services. For that purpose, a qualitative approach was used; in addition, an exhaustive review of all documents related to the Fondo, as well as six semi-structured interviews with the officials responsible for its implementation were conducted. It follows that the Fondo has positive aspects: productivity and projects completed, beneficiaries' satisfaction, and resource efficiency and reinvestment; however, it also has negative aspects: deficiencies in training of collaborators, insufficient materials, flickering communication channels, lack of knowledge about normativity, and lack of measurement indicators. This article's contribution is to analyze a sectoral and national policy, but considering territorial dimension in order to understand its implementation in a specific place, and thus to offer better results for beneficiaries.

Keywords: Fondo de Aportaciones para la Infraestructura Social; public policy; social welfare programs; social marginalization; state intervention; public expenditure; San Pedro Tlaquepaque.
\end{abstract}

Cómo citar: Arellano Ríos, A., Flores Ascencio, S. J., y Piedra Ascencio, R. I. (2019). Valoración del Fondo de Aportaciones para la Infraestructura Social, en San Pedro Tlaquepaque, Jalisco. región y sociedad, 3 I, e I037. doi: I0.22 | 98/rys20 | 9/3 |/ 037

* Autor para correspondencia. El Colegio de Jalisco. Calle 5 de Mayo \#321, C. P. 45100. Zapopan, Jalisco, México. Correo electrónico: alberto.or.arellano@gmail.com

** Unidad de capacitación del gobierno municipal de Zapopan. Francisco J. Mujica \#565, Unidad Habitacional Los Belenes, C. P. 45157. Zapopan, Jalisco, México. Correo electrónico: joelwolfox@hotmail.com

*** Secretaría de Movilidad de Jalisco. Naciones Unidas \# 4819-6, Jardines Universidad, C. P. 45110. Zapopan, Jalisco, México. Correo electrónico: roberto.piedra10@gmail.com

Recibido: 7 de febrero de 2018

Aceptado: 1 de agosto de 2018

Liberado: 27 de febrero de 2019

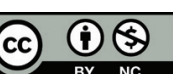

Esta obra está protegida bajo una Licencia

Creative Commons Atribución-No Comercial

4.0 Internacional. 


\section{Introducción}

Las investigaciones sobre políticas públicas en materia social tienden a concentrarse en ciertos casos de estudio, y con frecuencia acaparan el interés de la comunidad académica; algunos ejemplos de ello son el Programa Nacional de Solidaridad, el Programa de Educación, Salud y Alimentación, el Programa de Desarrollo Humano Oportunidades y el Programa de Inclusión Social Prospera, acerca de los cuales se han emprendido numerosas investigaciones, publicado cientos de materiales y abierto incontables foros para discutir sus alcances, vicisitudes, fortalezas y debilidades.

Hay políticas y programas que se estudian más que otros, desde luego esto va en detrimento de los que se analizan menos, pero que también son relevantes, como es el Fondo de Aportaciones para la Infraestructura Social (FAIS), que se encuentra lejos de la lente académica y gubernamental, a pesar de ser una fuente importante de ingresos para los estados y municipios y de estar orientado a paliar la pobreza más apremiante.

Aquí se pretende darle mayor importancia al estudio del FAIS y sus resultados, y aunque la ausencia de conocimiento no lo convierte en un objeto de estudio relevante, sí lo es el hecho de que la mayoría de los municipios ejerce un fondo que carece de un intercambio de experiencias entre quienes lo operan y quienes lo estudian formalmente desde afuera. Al respecto, es necesario recalcar que en este artículo se analiza una política sectorial y nacional, pero considerando la dimensión territorial, es decir, intenta comprender de manera especial cómo se implementa en un lugar específico dentro de un entramado complejo de actores e instituciones participantes.

Si bien en la jerga metodológica esta investigación se puede clasificar como un estudio de caso, teóricamente se inscribe en el análisis de una política pública con perspectiva territorial, enfoque que está comenzando a destacar en la medida que el territorio no es un simple contenedor de cosas, personas y actividades, sino un espacio donde se hace presente una realidad compleja y multidimensional (Arellano, 2017; Muller, 2000, 2009); esto es así porque si se observa que pueden existir políticas “muy bien diseñadas” por los gobiernos centrales, el territorio da la pauta, pues es ahí donde surgen los problemas de implementación. Por lo tanto, este caso puede dar cuenta, desde una perspectiva sociológica, qué agentes e instituciones se deben considerar como los responsables directos de establecer este tipo de políticas en territorios análogos, y pensar en los problemas de implementación del FAIS en su conjunto. ${ }^{1}$

Un caso no se determina por su escala o tamaño, y si los hallazgos no se pueden revestir de "universalidad", debido a su historicidad, no se debe confundir "validez" con "generalización". De un estudio de caso es posible generalizar a partir de los elementos estructurales de una realidad. Así, la generalización es posible cuando se puede resaltar el caso típico, hacer comparación por analogía, dar con el caso robusto u obtener "inferencias indiciales". No es la "jerarquía metodológica" lo que da fortaleza en una investigación, sino el tipo de preguntas que se plantean y cómo se contestan. Si bien la generalización que se puede obtener por medio del estudio de caso es más limitada, frágil y modesta que la de algunas técnicas cuantitativas, aquí no es la escala sino el interés de privilegiar la profundidad lo que enriquece la investigación, además de que la "incertidumbre" e "invención" también se dan en los estudios de caso (Giménez, 2012). 
Entonces, esta investigación puede ilustrar un caso que de seguro guarda similitudes con otros en el territorio nacional, con el fin de que las personas que toman decisiones y operan el Fondo en sus entidades y municipios tengan una referencia acerca de cómo se desarrollan los procesos en otros lugares. Aquí se ofrece una cartera de vicisitudes con la cual se pueden comparar y conocer sus áreas de oportunidad y sus fortalezas, quienes así lo deseen.

Para cumplir con el objetivo se dispuso de un texto que analiza la implementación del FAIS en San Pedro Tlaquepaque. Para ello, primero se esbozan sus características generales, y luego sigue el trazo de las investigaciones que lo han analizado. Después se problematiza el FAIS de tal modo que se convierte en un objeto de análisis desde las políticas públicas, y para ello se precisan el enfoque de estudio y las coordenadas analíticas; en seguida se describen, de manera general, los rasgos sociodemográficos del territorio estudiado y se presenta la metodología empleada para obtener los hallazgos que le suceden en el orden propuesto. Al final se recapitulan, de forma puntual, los hallazgos y las aportaciones.

\section{El diseño del FAIS}

El FAIS es uno de los ocho fondos que componen el Ramo 33 (Aportaciones Federales para Entidades Federativas y Municipios). En términos monetarios es el cuarto más importante, y en 2017 representó 14.4\% del ingreso de los municipios del país. De este modo, su relevancia es estratégica para las entidades y los municipios que se esfuerzan por superar la pobreza y el rezago social.

La lógica del FAIS es redistributiva, es decir, los recursos que ejerce están etiquetados para la edificación de la infraestructura social básica cuyo fin es apoyar, por medio del financiamiento de obras y acciones sociales, a la población en pobreza extrema y a localidades con rezago social alto o muy alto. Esto, como se detallará más adelante, se realiza en sintonía con la Ley General de Desarrollo Social y con los criterios de atención a zonas prioritarias establecidos por las reglas de operación del Fondo.

Según el artículo 33 de la Ley de Coordinación Fiscal, los recursos económicos del FAIS se deben canalizar a las obras de infraestructura social básica como agua, drenaje y alcantarillado; urbanización municipal; electrificación rural y en colonias populares; infraestructura básica de salud, en educación y en el ámbito productivo; mejoramiento de vivienda y caminos rurales.

De forma general, el ejercicio del Fondo avanza por la ruta siguiente: los municipios reciben los recursos, que entrega el Poder Ejecutivo federal, que deberá ejercer lo aprobado en el presupuesto de egresos de la federación para el Ramo 33. Luego, la Secretaría de Hacienda y Crédito Público (SHCP) confiere los recursos a la Secretaría de Desarrollo Social (SEDESOL), que a su vez los entrega a los ejecutivos estatales, a través de la Secretaría de Finanzas. Dichos gobiernos ejercen el Fondo de Infraestructura Social Estatal (FISE), y otorgan los recursos 
correspondientes a los municipios en forma del Fondo de Infraestructura Social Municipal (FISM). ${ }^{2}$

Una vez que los recursos se convierten en obras en los municipios, sus gobiernos rinden cuentas de forma simultánea al gobierno federal, a través de la Auditoría Superior de la Federación (ASF) y a su entidad, por medio de los órganos de fiscalización. La rendición de cuentas ocurre en dos vías: a) el gobierno estatal tiene que informar a los entes fiscalizadores del FISE, en calidad de ejecutor directo y del FISM como enlace y b) las dependencias federales dirigen sus informes a la ASF y a las comisiones de Vigilancia y de Desarrollo Social de la Cámara de Diputados, con el objetivo de valorar y aprobar la cuenta pública correspondiente.

El FAIS resulta estratégico para los municipios del país en la medida en que, por su diseño, operación y monto, es uno de los mejor valorados al contar con cierta solidez institucional, pero esto no lo exime de algunas críticas, de las que se dará cuenta a partir del estudio de caso.

\section{El FAIS como objeto de estudio académico}

Como ya se mencionó, pese a la importancia del FAIS, en comparación con otras políticas, se ha estudiado poco aunque es probable que en el corto plazo se publiquen más investigaciones con enfoques diferentes del problema. No obstante, es necesario revisar los trabajos encontrados hasta el momento de elaborar este artículo, cuya intención es ubicar sus alcances y limitaciones, y posicionar la lente de observación y lo que se pretende abordar en el estudio de caso.

Para empezar, y en un sentido cronológico, está el informe realizado por Wellenstein, Núñez y Andrés (2006) para el Banco Mundial, que contiene cuatro conclusiones: a) el FAIS está dirigido a los pobres, quienes presentan mejoras significativas en sus condiciones, sin embargo, se recomendó precisarlas y focalizarlas en el ámbito municipal; b) no se encontró correlación entre las asignaciones a obras de agua y electricidad del FAIS con la falta de acceso a estos servicios; c) recomendar reglas de operación más claras y precisas, así como para mejorar la capacidad institucional, y dar mayores incentivos para los estados y municipios, además se detectó la falta de claridad en el objetivo del programa y d) recomendar más rendición de cuentas a escala municipal, para monitorear la eficiencia del gasto e incorporar procesos de aprendizaje, pues aunque aumentaron los recursos para los municipios más pobres, no se detectó correlación con el mejoramiento de sus condiciones.

Al año siguiente, el Centro de Estudios de las Finanzas Públicas de la Cámara de Diputados (CEFP, 2007) realizó un estudio sobre la repercusión del FAIS en el índice de marginación de los municipios. Entre la evidencia empírica que encon-

2 Cabe precisar que en este artículo, cuando se habla del FAIS se alude a los recursos dirigidos a los municipios. En algunas investigaciones se hace la distinción entre los destinados a las entidades y a los municipios, en cuyo caso toman el nombre de FISM. 
tró destaca que en 1296 municipios del país (53.2\%) había avances en el combate a la marginación; la nota informativa indicó que 130 municipios (46.35\%) empeoraban sus condiciones, mientras que para $12(0.49 \%)$ no existían datos. Los mayores avances se dieron en Tabasco, con 16 de 17 municipios; en Morelos, con 31 de 33, y en Campeche, con 10 de 11. En contraste, las entidades con más municipios en retroceso fueron Coahuila, con 34 de 38, y Durango, con 34 de 39 (CEFP, 2007, p. 3).

El CEFP encontró que los recursos municipales per cápita eran insuficientes en términos reales. Además, se evidenció que entonces había falta de trasparencia en el seguimiento de los recursos que se distribuían a los municipios del país, e igual pasaba con su entrega en tiempo y forma, aunado al indicio de que "muchas obras quedaban inconclusas". Ciertamente los recursos eran insuficientes, pero tampoco había una instancia que les diera seguimiento a los proyectos.

Lo que el FAIS hacía en 2007, y aún lo hace, es “premiar” a los municipios más pobres y marginados, lo cual provocaba una suerte de efecto negativo no intencionado, al incentivar que éstos no buscaran recursos adicionales a los otorgados por el gobierno federal. Por consiguiente, ante el hecho de que la distribución no parecía ser clara, el órgano técnico de la Cámara de Diputados sugería cambios; por ejemplo, recomendó establecer una figura legal que impulsara la infraestructura, facilitara la inversión privada, agilizara proyectos de planificación y promoviera la inversión (CEFP, 2007, pp. 7-8).

En ese mismo año y con un enfoque econométrico, Hernández y Jarillo (2007) estudiaron el FISM; la preocupación analítica era saber si se distribuía con criterios compensatorios. Ellos encontraron que el FISM, contextualizado como política de tipo regional y en un proceso de descentralización, contenía un criterio redistributivo débil, ya que el dinero que recibían los municipios por parte de los gobiernos estatal y federal contenía un espacio considerable de discrecionalidad. Este hecho estaba relacionado con una variable político-económica donde el poder de negociación, el poder económico del municipio y el tamaño de su población determinaban la asignación del recurso. El sesgo en la trasferencia se evidenciaba cuando, por un lado, se observó que era difícil lograr el desarrollo de las comunidades que contaban con una población aislada y dispersa ( $25 \%$ del total del país) $y$, por el otro, que no había un marco legal fuerte. ${ }^{3}$

Después, Cejudo y Gerhard (2010) resaltaron que los estudios sobre el FAIS eran escasos. Desde entonces a la fecha se han sumado, a cuenta gotas, más investigaciones, y es probable que en el corto plazo aumenten considerablemente. Esta inquietud parte de que dichos autores señalaron que en 2009 el programa Oportunidades ejercía 47 mil millones de pesos y el FAIS 37 mil, sin embargo acerca de Oportunidades se han realizado muchos trabajos académicos y el FAIS se encuentra lejos de despertar el mismo interés.

3 Vale la pena precisar que, desde 2017, el FAIS tiene un marco normativo y diseño más sólido desde la federación, sin embargo el problema analizado aquí gira en torno a la fase de implementación en el llamado ciclo de política pública (policy cycle) en un territorio específico, el cual se busca sea significativo. 
No obstante, la inquietud de Cejudo y Gerhard (2010) fue demostrar que el FAIS tenía un déficit serio en la rendición de cuentas. Después de contextualizarlo y delinearlo, concluyeron que sus mecanismos de operación no satisfacían la rendición de cuentas, que se basaba en flujos de información simple sobre montos ejercidos, obras realizadas o materiales adquiridos, pero no daba cuenta de los resultados más allá de lo tangible. Con base en la información analizada, se concluyó que eran comunes las irregularidades y anomalías en la ejecución de los recursos federales como pagos con fines distintos a los establecidos, multas y recargos por pagos extemporáneos, incumplimiento a proveedores, otorgamiento de anticipos superiores a los previstos, inobservancia en los sistemas de calidad, obras que no beneficiaban a un grupo social rezagado, adjudicaciones indebidas, obras pagadas y no ejecutadas y falta de documentación probatoria, entre otras.

Para trasformar dichas prácticas, Cejudo y Gerhard (2010) proponían revisiones de desempeño y no solo auditorías financieras. Sugerían que el Fondo se evaluara por organismos técnicos, autónomos y externos, y que la rendición de cuentas no fueran simples reportes de avances de obras o pagos. Además, encontraron que faltaban mecanismos para que el ciudadano se enterara de su desempeño.

Ramones y Prudencio (2014) examinaron los efectos del FAIS en el ámbito estatal, del año 2000 a 2010. Desde una perspectiva económica, se encontró una relación nula o muy débil entre el monto asignado y las medidas para combatir la pobreza, y aunque la fórmula de distribución del Fondo representa un avance en el mecanismo de adjudicación de los recursos no estaba exenta de críticas pues, de alguna manera, se "penalizaba" a los estados y municipios que disminuían la pobreza. A decir de los autores, el FAIS tiene efectos perversos, porque los recursos no estaban necesariamente focalizados en reducir la pobreza extrema. Entonces, además de sugerir una fórmula nueva, enfatizaron que hay "fragilidad" en la administración de las autoridades que los manejan, por lo que es necesario hacer trabajo de campo.

Vázquez y Reyes (2016) desde un principio propusieron utilizar una parte del FAIS para incentivar el mecanismo de distribución y mejorar el bienestar social. Ellos trabajaron en los 58 municipios de San Luis Potosí, con la medición de 13 variables de desarrollo social y cinco de gestión pública. Se percataron de que el FAIS se puede calificar como exitoso visto desde la perspectiva de las entidades federativas, mas no desde los municipios. Propusieron que el monto concursable del FISM fuera de $25 \%$, y que se otorgara a los municipios que disminuyeran la pobreza. Esto traería como consecuencia la modernización de dichos gobiernos aludiendo que la descentralización ha sido necesaria pero no suficiente, puesto que la Ley de Coordinación Fiscal no tiene incentivos para premiar.

Así, al exponer las investigaciones anteriores, cabe resaltar las características de esta, y precisar que si bien es un estudio de caso ante las miradas nacionales y/o económicas, en él hay elementos que coinciden con los estudios 
mencionados pero, dado su enfoque, busca aportar mayores luces sobre el FAIS. Se hizo una investigación cualitativa con trabajo de campo, con una perspectiva de política pública ocupada en la implementación del FAIS y en un territorio específico.

\section{El enfoque de estudio y las coordenadas analíticas}

Para el análisis del FAIS en San Pedro Tlaquepaque, la lente primaria de observación es el enfoque de políticas públicas, surgido después de la segunda guerra mundial, con la intención de realizar estudios por los medios intelectuales, normativos y técnicos, para definir, diseñar y organizar la intervención del Estado. Por lo tanto, permite precisar las razones que explican una decisión pública con la que se busca ser más eficaces en su diseño e implementación, como la clave para entender la capacidad del Estado para resolver sus problemas principales (Merino, 2013, pp. 31 y 36).

Este artículo descansa en tres elementos analíticos: a) el focus será la implementación del FAIS, comprendido como un programa y acciones gubernamentales específicas; b) la corriente evidence-based policy (política basada en evidencia) es el soporte teórico, en el sentido de que se evaluó su efectividad real y hay evidencia de que ayuda para la toma de decisiones y para rediseñarla y c) la dimensión territorial ante las particularidades y la complejidad de la realidad implica un "enfoque territorial en las políticas públicas”, el cual desde hace tiempo despierta mucho interés en este campo disciplinar (Arellano, 2017, pp. 14-17; Muller, 2000, 2009).

Lo anterior significa que la implementación de las políticas públicas está sujeta a una diversidad de condiciones que erigen "el campo de batalla", que es el espacio donde habrá de desenvolverse la puesta en marcha de la política pública ya diseñada (Merino, 2013, p. 110). En la implementación se debe partir del principio de "racionalidad limitada", puesto que las preferencias de los actores involucrados pueden cambiar con el tiempo, la información no está disponible por completo durante el diseño o bien es posible que cambie, por el juego de intereses que la política pública puede generar; este principio también se debe tomar en cuenta, dado que el tiempo y los recursos destinados a la implementación son escasos (Merino, 2013, p. 117).

Al analizar el proceso de implementación, será importante estar atentos a la comunicación, al liderazgo asignado a las personas o equipos de trabajo, así como al cuidado de los indicadores de resultados, y considerar la interacción de los dos criterios (Merino, 2013, pp. 117-118); entonces, dicho proceso se vuelve un fin en sí. Con la teoría de las organizaciones hay coincidencia analítica cuando las rutinas burocráticas, entendidas como tareas y prácticas cotidianas interiorizadas, se traducen en procedimientos repetitivos y estables en las organizaciones públicas (Merino, 2013, p. 137); ante eso, los gobiernos municipales, en los cuales se presenta una diversidad y complejidad de rutinas e inercias ar- 
gumentativas, el trabajo de campo es útil para describirlas y para explicitarlas. Se deberá poner atención en los procedimientos decisorios de cada etapa de la política pública, en las características de la organización, en sus tiempos, recursos, incentivos y cumplimiento (Merino, 2013, pp. 138-146).

La corriente de "las políticas basadas en evidencia" defiende la pertinencia de un uso explícito e intencional de la mejor evidencia de investigación disponible. Empíricamente, con el caso de estudio se busca producir evidencia que aporte elementos de retroalimentación a la política pública en cuestión, para que se tomen mejores decisiones (Bracho, 2010, p. 292). Aunque hay cuestiones que juegan en contra, desde esta perspectiva (Bracho, 2010, pp. 298-301), la política basada en evidencia aplica investigación con procedimientos rigurosos y sistemáticos para la recolección de datos, y se preocupa por la trasformación de decisiones gubernamentales a partir de un conocimiento utilizable para la toma de decisiones. En ese sentido, los hallazgos de la investigación fueron en parte posibles debido a que, como menciona la corriente de la política basada en evidencia, aplicar la información técnica en la toma de decisiones le interesa y conviene a los actores gubernamentales, los académicos y al mercado de la evaluación de programas, por lo que todos tienden a cooperar. Lo anterior permitió el acceso a la información disponible, que se aceptaran los tiempos de la política y la voluntad de que la información obtenida se pudiera utilizar para mejorar el proceso de toma de decisiones y el desenvolvimiento de la organización (Bracho, 2010, pp. 311-313), esto en el gobierno de San Pedro Tlaquepaque, pero que por analogía se puede trasladar a otras realidades.

Aunque es posible ver al FAIS con un enfoque sectorial desde el ámbito nacional, la investigación adopta la perspectiva territorial. Se redescubre la dimensión local de las políticas públicas, es decir, la diversidad de situaciones y contextos, así como el hecho de que los problemas se manifiestan de manera desigual y diferenciada en territorios específicos. Las políticas públicas se encuentran entre una dimensión sectorial y territorial a la vez (Muller, 2000). Esto hace que se compartan las corresponsabilidades y la coordinación entre diversos entes gubernamentales sea fundamental (Muller, 2009); aunque el diseño y el control del FAIS se hacen desde la federación (Poder Ejecutivo y Poder Legislativo), su implementación corresponde a los gobiernos locales (estados y municipios); de ahí que el territorio sea importante como una cuestión de escala y también porque es donde se hacen presentes dimensiones, procesos y actores específicos en varios niveles y en tiempo real.

El enfoque territorial en las políticas públicas no solo considera la importancia del territorio en el diseño e implementación de los programas gubernamentales, sino que al tomarlo en cuenta supone un modelo de gestión que también sopesa la multidimensionalidad, la multisectorialidad y complejidad de actores e instituciones que pertenecen a escalas diferentes, pero que interactúan en tiempo y espacio real (Arellano, 2017). Con mayor claridad, la dimensión territorial es entonces uno de los elementos clave de la política pública, hace énfasis en que hay desequilibrios económicos y desigualdades sociales que se buscan subsanar. Y no hacerlo condicionaría fracasos múltiples, derivados de las competencias y 
las relaciones que se dan entre diversos ámbitos de gobierno (Adams, Cotella y Nunes, 2011).

La territorialidad en las políticas públicas toma en cuenta las circunstancias específicas, y esto lo hace un "enfoque integrador" para el desarrollo (Atkinson y Rossignolo, 2008). Derivado de lo anterior, los gobiernos locales y su administración pública asumen un "rol relacional" activo, convencidos de que en el proceso de implementación de una política central los fortalece en su liderazgo y en la capacidad de emprendimiento social de los funcionarios públicos (Mendoza y Vernis, 2008; Vernis y Mendoza, 2009).

\section{El municipio de estudio}

El municipio de San Pedro Tlaquepaque forma parte de la zona metropolitana de Guadalajara, ubicada en la región centro de Jalisco; cuenta con una superficie aproximada de $131 \mathrm{~km}^{2}$, limita al norte con Guadalajara, al noreste con Tonalá, al sur con Tlajomulco de Zúñiga, al sureste con El Salto y al poniente con Zapopan. La mayor parte de su territorio es plano, con algunos lomeríos y pocas tierras altas cerriles; su elevación máxima es el cerro del Cuatro, a 1870 msnm y la mínima se encuentra al sur, a 1530 (ver Figura 1).

En 2015, y según el Instituto Nacional de Estadística y Geografía (INEGI, 2015), el municipio tenía 664193 habitantes (ver Figura 2); 328802 eran hombres y 335 391 mujeres. En los últimos 20 años su tasa de crecimiento poblacional ha oscilado entre 1.67 y $1.90 \%$, su índice más alto fue de $3.07 \%$, registrado en el año 2000 (ver Figura 3), que es bajo en comparación con el de los municipios vecinos.

En 2010, el ayuntamiento reconocía la existencia de 98 colonias, 74 fraccionamientos y 13 zonas rústicas. Por otra parte, según la SEDESOL, en 2010 San Pedro Tlaquepaque tenía un grado de marginación muy bajo, en tanto que variable en las localidades que lo conforman. ${ }^{4}$

Según el Consejo Nacional de Evaluación (CONEVAL), en 2010 en el municipio había 161804 personas sin acceso a una alimentación básica para vivir, lo cual representa $27.6 \%$ de la población total; 8.4 estaba en situación de pobreza alimentaria; 15.6 en pobreza de capacidades, es decir, sin ingresos suficientes para adquirir la canasta alimentaria, y efectuar los gastos necesarios en salud y educación y, en 2005, 44.8 se encontraba en situación de pobreza de patrimonio, es decir, carecía del ingreso para adquirir la canasta alimentaria, pero también para cubrir los gastos de salud, vestido, vivienda, trasporte y educación, aunque la totalidad del ingreso del hogar fuera utilizado exclusivamente para la adquisición de estos bienes y servicios. ${ }^{5}$

4 http://www.microrregiones.gob.mx/catloc/contenido.aspx? refnac=140980001

5 Panorama Sociodemográfico del Municipio de Tlaquepaque (http://internet.contenidos.inegi. org.mx/contenidos/Productos/prod_serv/contenidos/espanol/bvinegi/productos/nueva_estruc/ inter_censal/panorama/702825082239.pdf). / Índices Sociodemográficos y Carencias en la Pobreza o Rezagos por Ingreso Tlaquepaque 2005. Consejo Estatal de Población-Gobierno de Jalisco: "Índice de rezago social en entidades y municipios 2005" (https://www.coneval.org.mx/Medicion/Paginas/Archivo-historico.aspx). 
Figura 1. Municipio de San Pedro Tlaquepaque, Jalisco

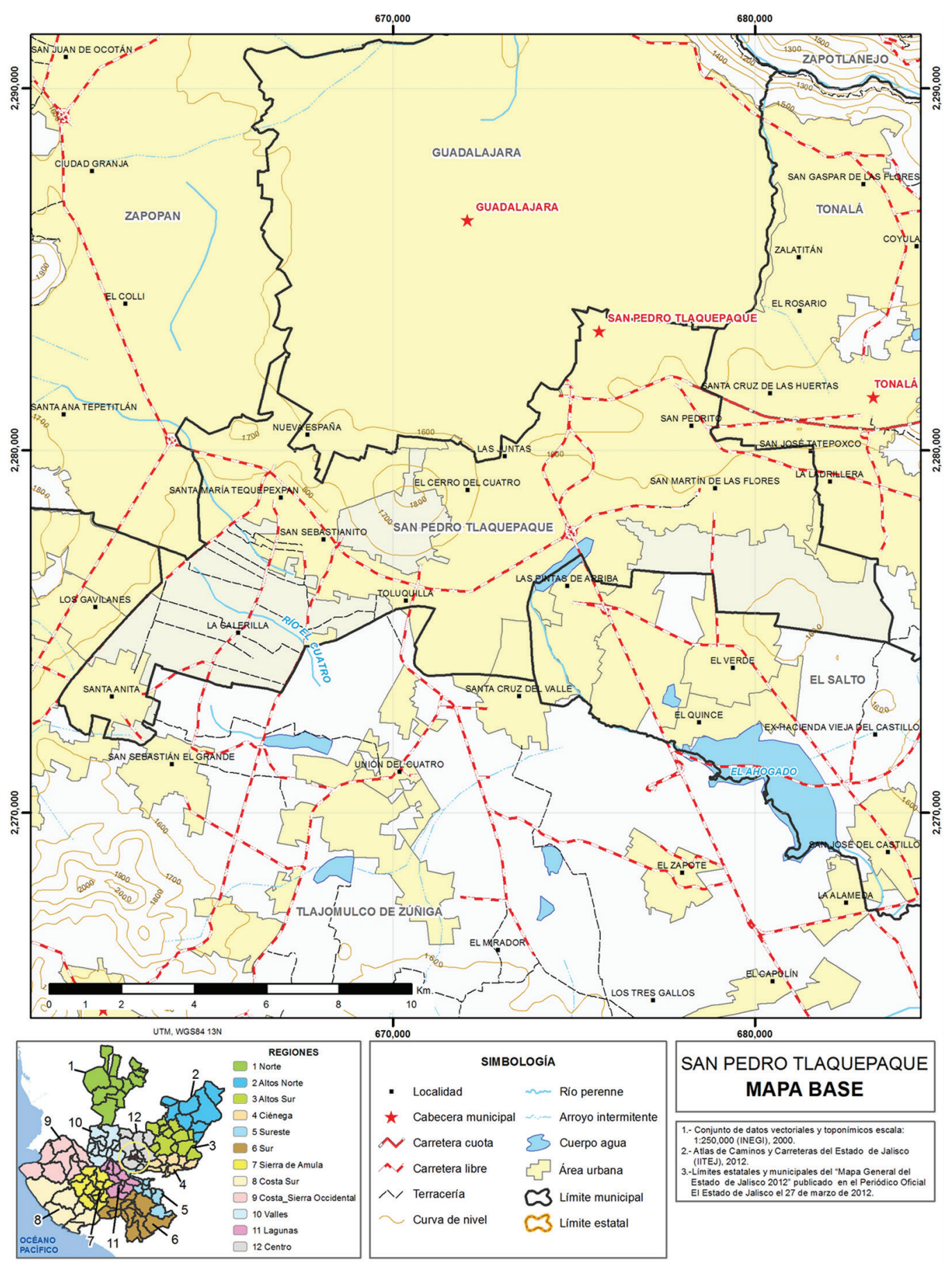

Fuente: Instituto de Información Estadística y Geográfica del Estado de Jalisco (http://www.iieg. gob.mx/contenido/GeografiaMedioAmbiente/SanPedroTlaquepaque_MBase.jpg). 
Figura 2. Población en San Pedro Tlaquepaque (1990-2015)

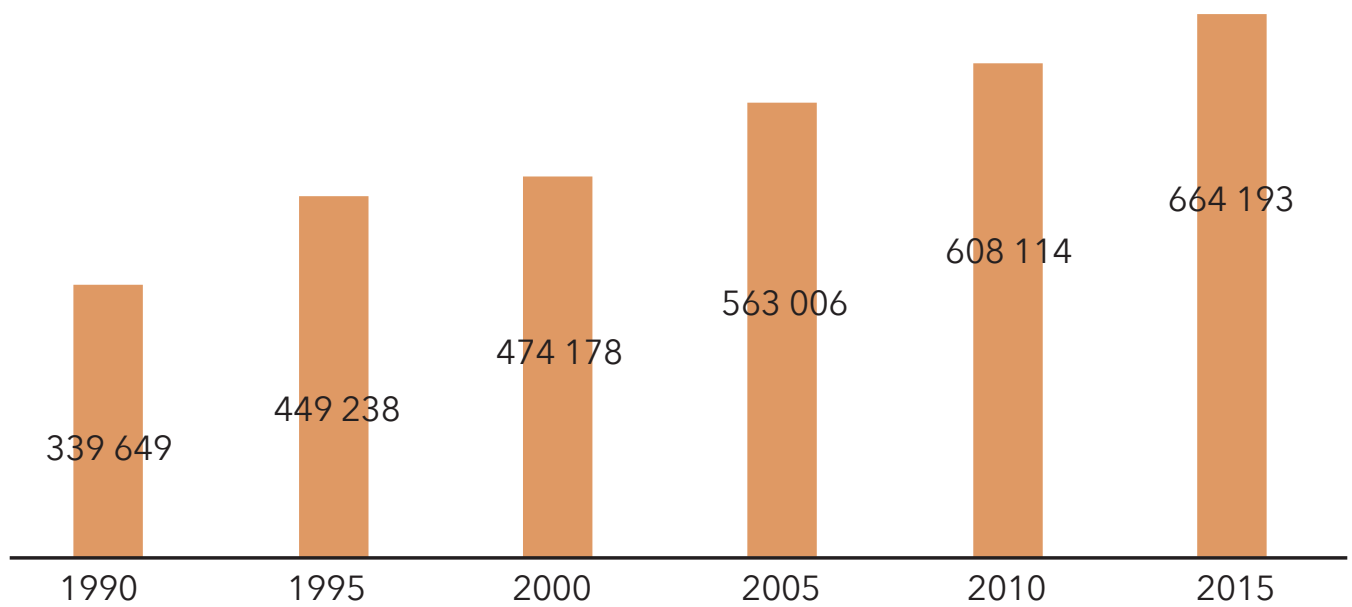

Fuente: elaboración propia, con base en la población en los municipios de México 1950-1990; Conteos de Población y Vivienda 1995 y 2005; XII Censo General de Población y Vivienda 2000, 2010 (http://www3.inegi.org.mx/sistemas/iter/consultar_info.aspx); INEGI (2015).

Figura 3. Tasa de crecimiento poblacional promedio anual en San Pedro Tlaquepaque (1950-2015)

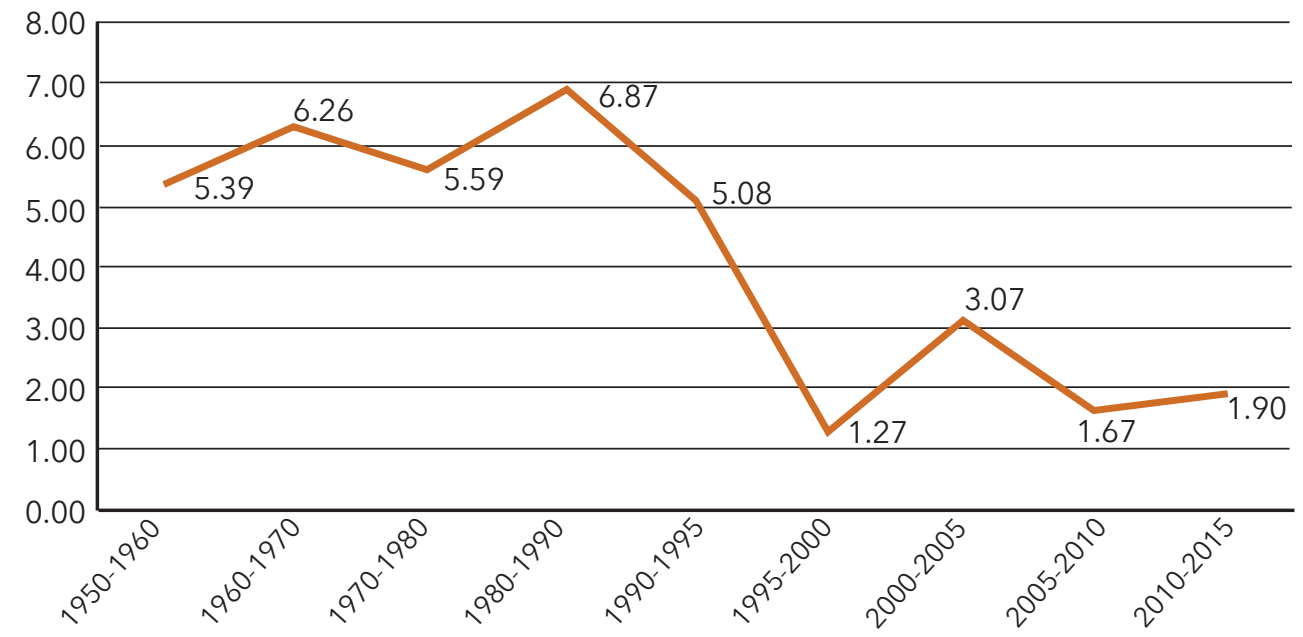

Nota: el análisis se hizo a partir de los periodos que abarcan los censos y conteos, que pueden ser de décadas o quinquenios.

Fuente: elaboración propia, con base en la población en los municipios de México 1950-1990; Conteos de Población y Vivienda 1995 y 2005; XII Censo General de Población y Vivienda 2000, 2010 (http://www3.inegi.org.mx/sistemas/iter/consultar_info.aspx); INEGI (2015). 
El punto anterior lleva a contextualizar otras cuestiones, como los indicadores de la marginación y la pobreza, por ejemplo la vivienda. En San Pedro Tlaquepaque, $15.3 \%$ de su población no tiene acceso a una vivienda digna con servicios básicos; 25.20 posee una en asentamientos humanos irregulares; 8.5 de ésta es de mala calidad y con espacios deficientes, en tanto que 9 tiene accesos precarios a los servicios básicos en la vivienda. Uno de los aspectos más significativos en este rubro es que el municipio cuenta con una de las superficies de asentamientos irregulares más grandes en el país, que abarca 1650 hectáreas, lo que representa $30 \%$ del área urbanizada.

Por otra parte, el CONEVAL (2010) reportó que 32.5\% de la población no tenía acceso a los servicios de salud, mientras que la escolaridad de los tlaquepaquenses de 15 años y más era de 8.8 años.

En relación con el servicio de agua potable, los problemas de abastecimiento estaban focalizados en las colonias ubicadas en el cerro del Cuatro, así como en los límites con los municipios de Tonalá y El Salto; según el Sistema Intermunicipal de Agua Potable y Alcantarillado, 25 colonias carecían de agua potable, y se les suministraba con pipas; por su parte, 7000 viviendas no contaban con drenaje y alcantarillado, y la cobertura de energía eléctrica era de 93\% de las viviendas.

Uno de los datos principales para entender la importancia de las características institucionales de San Pedro Tlaquepaque es que en 2017 su gobierno ejerció aproximadamente 1500 millones de pesos, de los cuales 555 fueron ingresos propios; 58 provinieron del FAIS; 327 del Fondo para el Fortalecimiento Municipal; 524 de participaciones federales y 79 de estatales. ${ }^{6}$ En cuanto a la nómina del gobierno municipal, la burocracia rondaba en los 4000 servidores públicos. $^{7}$

Por lo anterior, el caso de estudio es significativo en la medida que San Pedro Tlaquepaque está integrado a una zona metropolitana, pero es periférico al central. Tiene 670000 habitantes, cuya marginación es muy baja, pero en su territorio persisten problemas de marginación y pobreza muy focalizados en ciertas áreas geoestadísticas básicas, en términos del INEGI o en las llamadas zonas de atención pioritaria (ZAP), que determina la SEDESOL, en virtud de la atribución que le confiere la Ley General de Desarrollo Social.

\section{Metodología}

Para conocer el desempeño del FAIS en San Pedro Tlaquepaque, reflejado en sus procesos de implementación, se empleó un enfoque cualitativo, pero no exclusi-

6 En 2015, el presupuesto fue de 1584719.757 pesos. Los ingresos propios ascendieron a 555190 201 pesos. Del fondo para infraestructura se sumaron 57827 239; el fondo para el fortalecimiento municipal fue de 327334 900; las participaciones federales de 54216926 y las estatales de 79 118 150. Los ingresos restantes provinieron de convenios u otros recursos (https://transparencia. tlaquepaque.gob.mx/wp-content/uploads/2016/01/Presupuesto-de-Egresos-2015-1.pdf).

7 Según el portal de transparencia de San Pedro Tlaquepaque, en la segunda quincena de septiembre de 2017, había 2600 empleados de nómina general, 1023 de seguridad pública, 465 por honorarios y 153 pensionados (https://transparencia.tlaquepaque.gob.mx/nomina/). 
vamente. La investigación se realizó de diciembre de 2016 a febrero de 2017, y se estudió el ejercicio fiscal de 2015, para comprender las interacciones entre el personal con alguna responsabilidad en la operación del FAIS, y los resultados de ellas en términos de consistencia en el cumplimiento del proceso y el desempeño. Primero se efectuó un trabajo de gabinete intenso, por medio de la revisión exhaustiva de todos los documentos relacionados con el Fondo. ${ }^{8}$

Luego se realizaron seis entrevistas semiestructuradas a los funcionarios implicados en la implementación del Fondo, provenientes de varias dependencias y con perfiles distintos, el requisito imprescindible fue que participaran de manera activa en el ejercicio del FAIS. ${ }^{9}$ Aunque para algunos pudieran ser pocas las entrevistas formalizadas, la observación en campo y entrevistas informales llevaban al punto de saturación.

Después se integró un grupo de enfoque, para lo que se eligió a cuatro servidores públicos, por recomendación de la organización. Ellos trabajaron en el proceso del FAIS 2015, era uno por cada área municipal: Obras Públicas (Coordinación de Gestión Integral de la Ciudad), Contraloría Ciudadana, Tesorería y Dirección de Políticas Públicas, ${ }^{10}$ así se cuidó la heterogeneidad del grupo.

También se consideró el contacto con los beneficiarios para comprender los procesos del FAIS, desde una perspectiva distinta a la eminentemente gubernamental. Para ello se eligió al azar tres obras realizadas con el FAIS: una de agua potable, otra de drenaje sanitario y una de revestimiento con empedrado zampeado. Las entrevistas se hicieron en el domicilio de tres ciudadanos, quienes fueron seleccionados por ser beneficiarios directos, mayores de edad y por haber vivido de cerca el proceso de la realización de las obras. Después de una presentación breve y una vez generada la confianza necesaria, los investigadores hicieron las preguntas en voz alta, y los entrevistados respondieron de la misma manera, y se tomó nota de las respuestas. ${ }^{11}$

\section{El FAIS en San Pedro Tlaquepaque}

En 2015, el monto destinado al FAIS en el país ascendió a 58502953.016 pesos; 7091407.201 se turnaron a los estados y 51411545.815 a los municipios, y 2

8 El trabajo de gabinete consistió en el acopio, organización, sistematización y valoración de información contenida en registros administrativos, bases de datos, documentos oficiales y normativos y sistemas de información, entre otros. Este análisis se centró en la apreciación tanto de los aspectos normativos como del marco contextual en el que se desarrolló el FAIS en 2015.

9 En esta fase de la investigación queremos agradecer la participación de Marisela Barajas Baro, de la Dirección General de Políticas Públicas; Rogelio Navarro, de la Tesorería; Claudia Dámazo, del Departamento de Construcción (Obras Públicas); Elizabeth Contreras, del Comité de Planeación para el Desarrollo Municipal; Rosendo Bautista, de Contraloría y a Jaime Velasco, de Obras Públicas.

10 En esta parte de la investigación se agradece la participación de Guillermo Martínez Suárez, de la Dirección de Auditorías Estratégicas; Adán Ramírez Gutiérrez, de la Dirección de Obras y Proyectos; Rogelio Navarro Hernández, de Hacienda municipal y Marisela Barajas Baro, de la Dirección General de Políticas Públicas.

11 En relación con la obra de drenaje sanitario, se entrevistó a Martha, de la colonia Ojo de Agua (calle San Fernando entre San Paulo y Antiguo camino a Toluquilla); para la obra de empedrado zampeado en la colonia Francisco I. Madero (de la calle Mariano Moreno, entre Santa Rosalía y Lienzo de piedra), se entrevistó a Ofelia; en tanto que a Héctor Manuel para la de agua potable, en la colonia Nueva Santa María (de la calle Santa Elena, entre Andrés Tamayo y San José). 
367 de ellos recibieron recursos y llevaron a cabo 91074 proyectos, la mayoría de servicios básicos y vivienda. ${ }^{12}$

En Jalisco, de 2009 a 2015 el presupuesto del FISM ha tenido una tendencia ascendente, salvo en 2011 y 2012, cuando tuvo el mayor y menor respectivamente. El presupuesto otorgado a San Pedro Tlaquepaque fue de $4.48 \%$ y de 5.91 del recurso total del FISM en el estado (ver Tabla 1).

Tabla 1. Presupuesto anual del FISM 2009-2015, en Jalisco y en San Pedro Tlaquepaque. Millones de pesos

\begin{tabular}{|c|c|c|c|}
\hline Año & Jalisco & San Pedro Tlaquepaque & $\begin{array}{c}\text { Porcentaje destinado } \\
\text { a San Pedro Tlaquepaque }\end{array}$ \\
\hline 2009 & 1126.18 & 59.40 & 5.27 \\
\hline 2010 & 1173.49 & 69.30 & 5.91 \\
\hline 2011 & 1313.48 & 63.94 & 4.87 \\
\hline 2012 & 1027.28 & 54.19 & 5.28 \\
\hline 2013 & 1116.66 & 58.90 & 5.27 \\
\hline 2014 & 1242.42 & 55.60 & 4.48 \\
\hline 2015 & 1260.33 & 57.25 & 4.54 \\
\hline
\end{tabular}

Fuente: elaboración propia, con base en datos de Transparencia Fiscal (http://transparenciafiscal. jalisco.gob.mx/content/fondo-de-aportacion-para-la-infraestructura-social-municipal-faism) y del portal de Transparencia del Municipio de San Pedro Tlaquepaque (https://transparencia.tlaquepaque.gob.mx/).

Aunque el estudio se centró en 2015, se realizó un ejercicio de retrospectiva de 9 años, ${ }^{13}$ con la finalidad de conocer los montos históricos del FAIS en San Pedro Tlaquepaque. La evidencia recolectada muestra que desde 2009 existe estabilidad en los recursos asignados por la federación a este municipio. En 2008 se aprobó una cantidad menor, alrededor de 9 millones de pesos. En contraste, en 2010 se alcanzaron casi los 70 millones. En los últimos años el presupuesto ha rondado los 60 millones (ver Figura 4).

Para 2015, el Ayuntamiento de San Pedro Tlaquepaque aprobó un presupuesto de 56858 685.00, al que se le añadieron 391896.00 de remanentes de ejercicios anteriores, para sumar 57250 581.00. De estos recursos, 55.26\% se utilizó en obras de incidencia directa y 44.74 de indirecta, superior a $30 \%$ que señalan los lineamientos generales para la operación del FAIS. En el ejercicio que se estudia, la mayor proporción de las obras llevadas a cabo fueron alcantarillado, agua potable y vialidades (ver Figura 5).

12 https://www.gob.mx/cms/uploads/attachment/file/114644/Presentaci_n_FAlS_Nacional_2015. pdf

13 Este lapso abarca tres periodos de la administración municipal: 2007-2009, 2010-2012 y 2012 2015. 
Figura 4. Histórico de montos aprobados FISM, 2007-2015

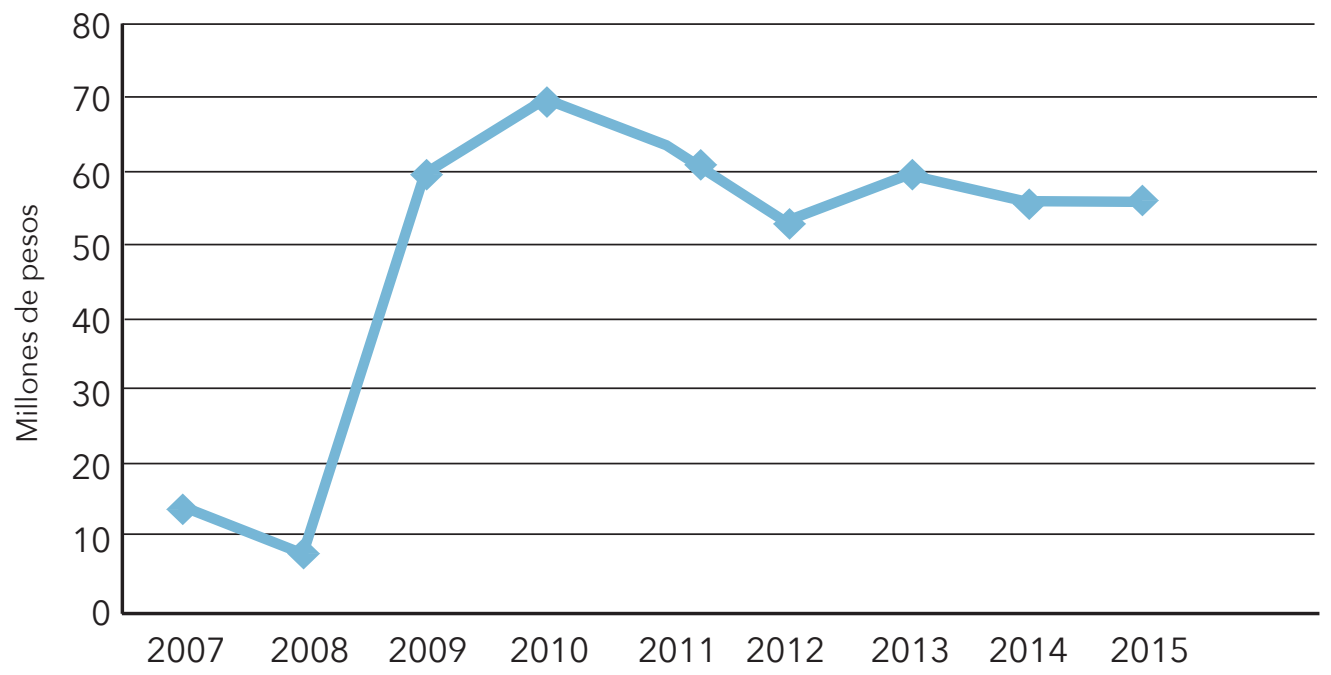

Fuente: elaboración propia, con base en información provista por el área de transparencia del municipio de San Pedro Tlaquepaque (https://transparencia.tlaquepaque.gob.mx/).

Figura 5. Tipo de obras aprobadas FISM, 2015

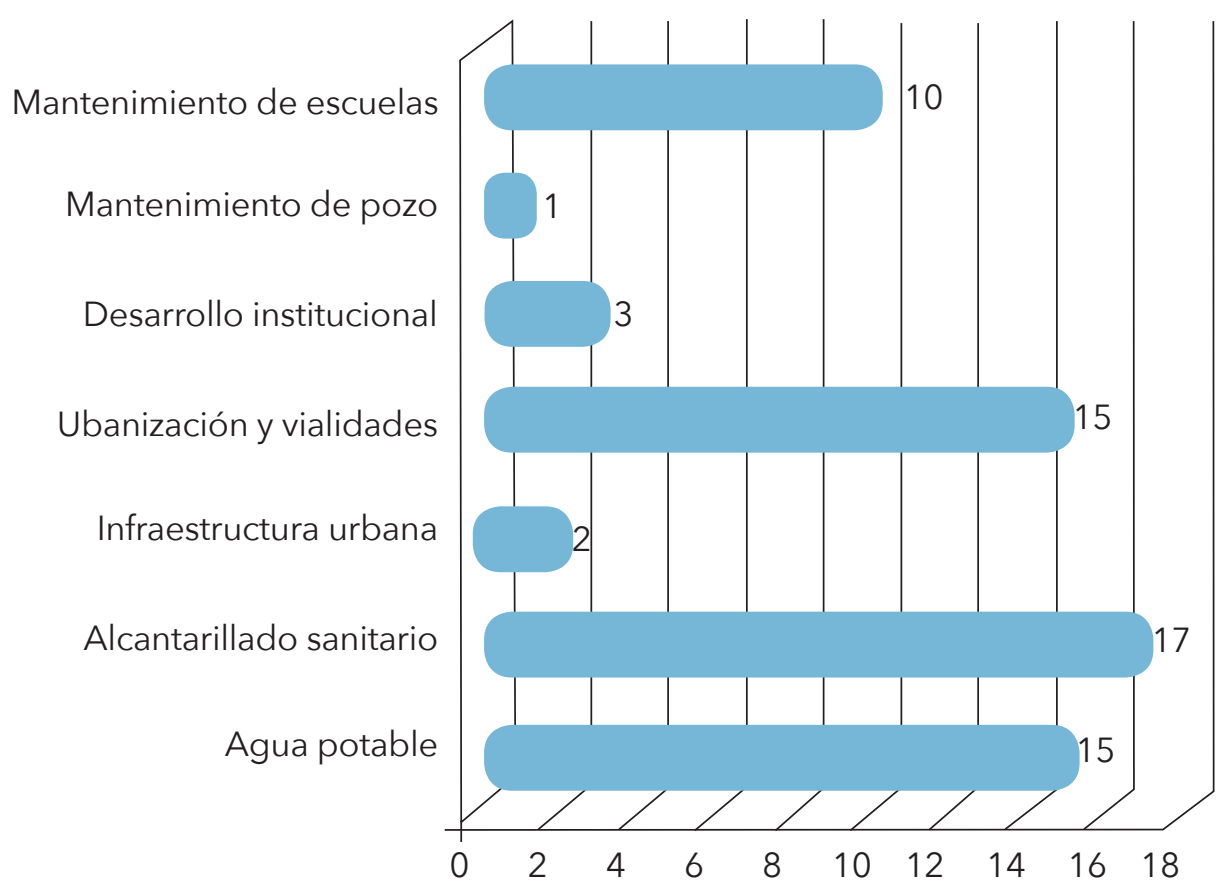

Fuente: elaboración propia. 
En virtud de que la población potencial por atender es la marginada, que justifica la existencia del Fondo, se encontró que las dependencias del municipio carecen de una delimitación formal que diferencie las localidades y zonas pertenecientes a la población potencial de la objetivo. Para resarcir esta limitación fue necesario identificar las localidades con rezago social alto y muy alto, las cuales se sumarían a las que residen en las ZAP. Esto implicaría que sería mucho más la población elegible para ser atendida, sin embargo, se sabe que no todas las localidades marginadas son sujetas de ser beneficiarias por ser irregulares (ver Figura 6). ${ }^{14}$

Figura 6. Localidades con mayor rezago social y ZAP urbanas en San Pedro Tlaquepaque, 2010

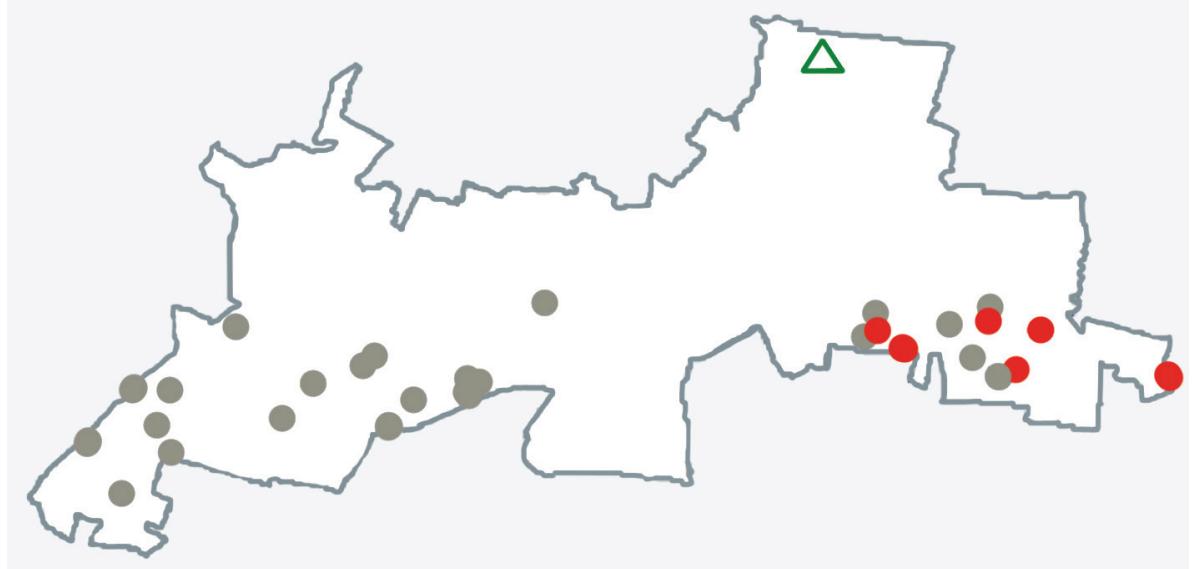

$\triangle$ Localidades con ZAP urbanas (1)

Localidades con los dos mayores grados de rezago social (6)

Otras localidades (24)

Fuente: Informe anual sobre la situación de pobreza y rezago social 2016, Subsecretaría de Planeación, Evaluación y Desarrollo Regional (http://diariooficial.gob.mx/SEDESOL/2016/Jalisco_098.pdf).

14 Pese a las limitaciones, el gobierno de San Pedro Tlaquepaque ha desarrollado el Sistema de Información Geográfica y Estadística Municipal, que contiene diagnósticos individuales amplios de las colonias, lo cual aporta elementos valiosos para la aplicación correcta de los recursos. Esta debe ser una exigencia para municipios de características similares. 
En relación con la lógica organizativa, la Dirección General de Políticas Públicas se encarga de la parte administrativa y de contacto con la SEDESOL, con el gobierno de Jalisco y con la SHCP; también de dar seguimiento a los procesos y coordinar la evaluación del FAIS. Además, organiza foros con los vecinos, ${ }^{15}$ porque les interesa incluir la participación ciudadana para la selección de obras susceptibles de ser financiadas con el FAIS. La Dirección de Obras Públicas elaboró proyectos, a la vez que ejecutó las obras seleccionadas; Tesorería se ocupó de abrir las cuentas correspondientes para el depósito de los recursos del FAIS, así como de pagar las obras finiquitadas correctamente, y la Contraloría Ciudadana verificó las obras en campo, y realizó las auditorías pertinentes (ver Figura 7).

Figura 7. Principales dependencias que intervienen en el proceso del FAIS en San Pedro Tlaquepaque

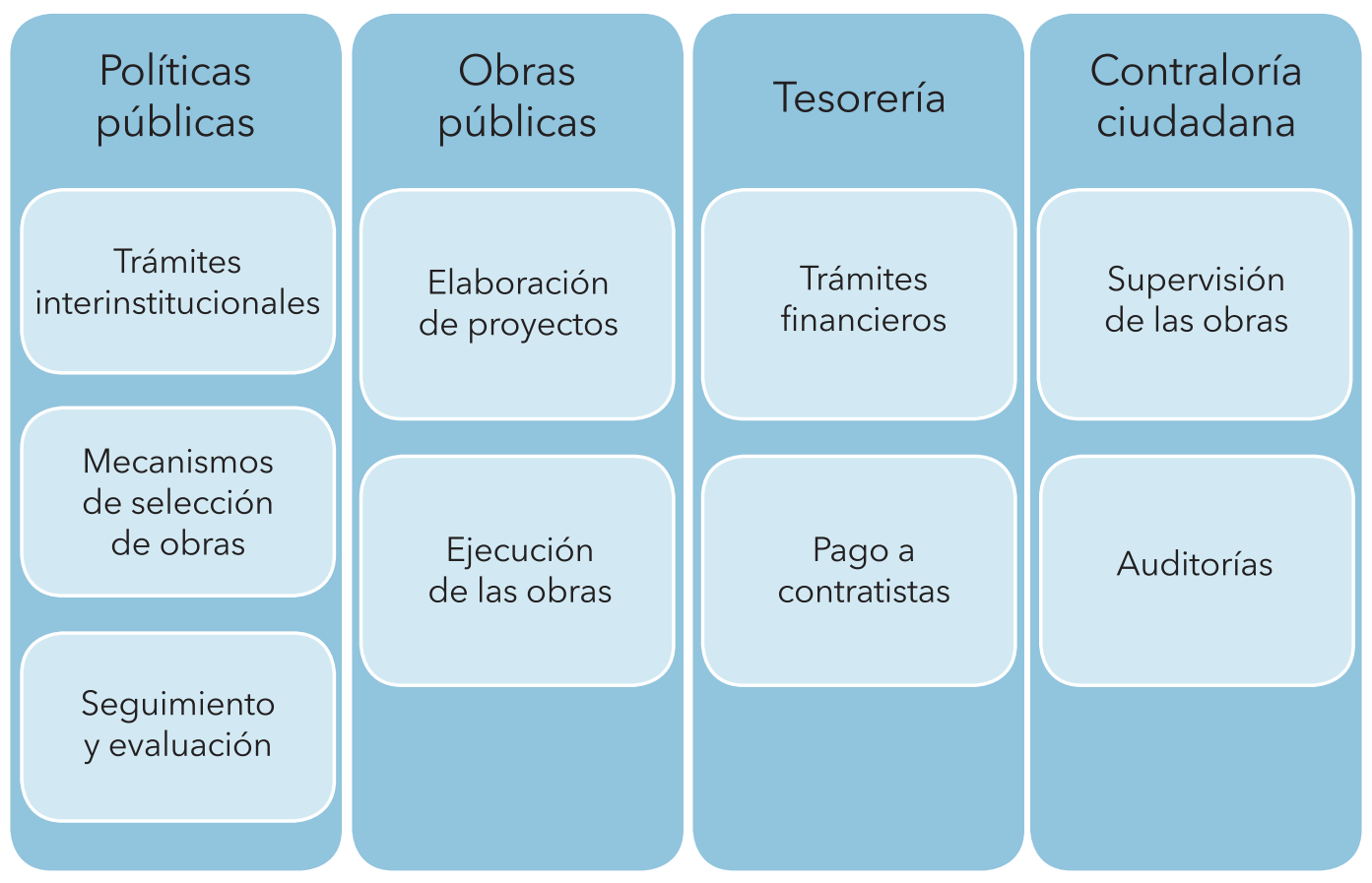

Fuente: elaboración propia.

15 San Pedro Tlaquepaque ha logrado la institucionalización de mecanismos participativos, a través de los cuales la ciudadanía tiene la posibilidad de incidir en la selección de las obras que se realizarán con el Fondo, tal es el caso de las mesas de trabajo organizadas por la Dirección de Políticas Públicas, lo que sin duda representa una práctica replicable, pues además de promover la participación ciudadana, se logra una vinculación sana entre gobierno y gobernados. 
En el trabajo de campo se observó que la implementación y ejercicio del FAIS en San Pedro Tlaquepaque se basa mayormente en los conocimientos y experiencia del personal. Estos componentes organizativos que operan se convierten en rutinas y prácticas y con ello se sobrellevan, de alguna manera, los cambios de gobierno o alternancia partidista. Como característica intraorganizacional, en el gobierno municipal la profesionalización es incipiente, toda vez que muchos de los funcionarios medios que operan el FAIS llevan años trabajando en la administración. ${ }^{16}$ Pese a esto, los cambios y factores político-institucionales inciden en forma negativa, en la medida que hay obras que no se concluyen en tiempo y forma y, por lo tanto, provocan retrasos y subejercicios que los órganos externos catalogan como irregularidades.

Ante esto, se observó que los componentes exteriores, es decir, la Ley de Coordinación Fiscal, la Ley Federal de Presupuesto y Responsabilidad Hacendaria, la Ley General de Contabilidad Gubernamental y los lineamientos del FAIS no se hicieron del conocimiento de sus operadores o con la actualización requerida. En el periodo evaluado, en el gobierno municipal tampoco existía un manual de procesos diseñado para ejercer el FAIS; lo cual genera que no se encuentren debidamente estandarizados y, por ende, la información de las actividades que lo conforman en ocasiones se encuentra dispersa.

Los funcionarios y los servidores públicos involucrados en los procesos del FAIS lo califican como positivo en términos generales, en comparación con otros fondos federales y programas propios. Los aspectos referidos con más frecuencia son: la productividad, traducida en la gran cantidad de obras realizadas ese año; la eficiencia, por el ahorro y reinversión de recursos, y el cumplimiento de los tiempos de entrega establecidos. También hay aspectos negativos, como la falta de capacitación al personal, la ausencia de las herramientas materiales necesarias en algunos casos y el flujo intermitente de información entre dependencias. Aunado a lo anterior, el FAIS es bien visto por los funcionarios municipales porque los recursos se entregan a tiempo, y su recepción no genera preocupación entre los operadores. ${ }^{17}$

Un elemento técnico y de gestión interno por considerar es que no se cuenta con un sistema de información en el que los participantes en el proceso de implementación del FAIS (que incluye a los contratistas) tengan la posibilidad de revisar las estimaciones, la documentación de las obras y su estatus en tiempo real.

En cuanto al tema de la coordinación, es destacable que los funcionarios implicados conocen las actividades y responsabilidades propias de su puesto;

16 En términos generales, el personal del gobierno de San Pedro Tlaquepaque que opera e interviene en el FAIS cuenta con el perfil adecuado, logrado más por su vasta experiencia que por capacitaciones recibidas. En algunos casos (sobre todo en Obras Públicas) el personal se queja de sobrecarga de trabajo, y que éste se ha incrementado en mayor medida que el personal que lo ejecuta.

17 Otra valoración positiva es que las obras de infraestructura gozan de aprobación general, pues se trata de polígonos muy necesitados de infraestructura social básica. Sin embargo, en cuanto a los procesos que implican las obras entregadas, sí hay puntos que destacar: los vecinos refieren errores técnicos de ejecución, incumplimiento de los propios vecinos del cuidado de la obra y mala calidad de los materiales en el caso del drenaje, entre otros. 
no obstante, hay obstáculos o fallas de comunicación entre ellos que impiden la implementación correcta del FAIS, a pesar de que en el trabajo de campo se pudo observar cierta camaradería entre el personal, lo que favorece la cooperación y coordinación entre las dependencias. En ocasiones, la forma de ejercer el mando ha interferido en el trabajo trasversal, en virtud de que predomina un estilo generalizado de actuación vertical, el cual detiene o entorpece el flujo correcto del proceso. ${ }^{18}$

Desde luego no todas las actividades o procesos que integran el ejercicio del FAIS tienen la misma importancia estratégica. Si el producto final principal es la entrega de obras de infraestructura, la construcción de ellas tiene una relevancia especial en el proceso general. A decir de los propios operadores, las actividades realizadas por la Dirección de Obras Públicas, en colaboración con los contratistas y que culmina en la entrega de una obra, son las que presentan más complicaciones, lo que fue confirmado en varios sentidos por la revisión documental.

Sin embargo, este hallazgo se presenta en un buen momento, para resaltar uno muy particular: en 2015 el gobierno municipal otorgó una ponderación tan considerable a la obra pública, que incluso a pesar de la gran cantidad de acciones de infraestructura pendientes y de lo abrumador que resulta para ellos ejercer el Fondo, además realizaron obras con recursos propios provenientes de otras fuentes de financiamiento. En otras palabras, la iniciativa por construir y entregar obra pública podría ser superior a la capacidad técnica y operativa para lograrlo de manera satisfactoria, por lo que valdría la pena, en investigación aparte, ponderar si resulta más adecuado disminuir la cantidad de obras en aras de terminarlas más rápido, o abrir la mayor cantidad de frentes posibles y sortear su culminación, como se hizo ese año.

Un elemento muchas veces olvidado, señalado por Cejudo y Gerhard (2010), es que la rendición de cuentas o una valoración más allá de elementos contables o la entrega de las obras era y es la satisfacción de los beneficiarios. En el caso estudiado se observó que existen, aunque de manera muy elemental, algunos mecanismos para externar opiniones, quejas y observaciones sobre las obras realizadas en los alrededores de la vivienda, además de que se les hace saber a los vecinos que en cualquier momento pueden solicitar audiencia con personal de alguna de las dependencias involucradas, por lo general de la Dirección de Políticas Públicas; asimismo, existe un formato conocido como acta de entrega-recepción y finiquito de obra, sin embargo, éste no incluye la retroalimentación acerca de los procesos de la obra, y de hecho ningún ciudadano plasma su firma, sino que solo intervienen actores gubernamentales y contratistas. En el mismo sentido, hay un buzón para que los ciudadanos depositen por escrito su opinión, pero sin especificar el fondo o programa al cual pertenece, por lo que se incumplen las instrucciones dictadas para dicho canal de comunicación.

18 Hay una identificación clara y un conocimiento muy preciso sobre los procesos del FAIS, y circunscrito a sus responsabilidades, lo cual resulta deseable y se considera como una fortaleza, en la medida que facilita la ejecución de su trabajo y minimiza errores con ayuda de la experiencia. Lo mismo ocurre con la forma en cómo se identifican los actores y las instituciones principales en la implementación del FAIS. 
En términos generales, el FAIS se apega a la normatividad vigente, pero pudieran existir irregularidades como las señaladas por otros estudios. El trabajo de campo permite indicar que en la implementación se presentan algunos "cuellos de botella", entendidos como prácticas, procedimientos, actividades y/o trámites que obstaculizan procesos de los que depende el programa, para alcanzar sus objetivos.

Los cuellos de botella identificados, y que por analogía deben considerar municipios similares a San Pedro Tlaquepaque, o aquéllos con mayor solidez institucional son:

1. La falta de capacitación. Una de las deficiencias más acuciantes para el personal que operó el FAIS. Algunos asistieron a capacitaciones ofrecidas por instancias federales, pero éstas no se difundieron entre todos. En el caso de estudio no hay capacitación formal y organizada, ya que la existente es acerca del llenado y cumplimiento de reportes, por lo general para otros órdenes de gobierno, y centrados en lo relativo a la trasparencia y el uso de recursos, que sin duda resultan de utilidad, pero no satisfacen las necesidades de actualización, formación y crecimiento del personal.

2. La comunicación interna. En las dependencias que intervienen en el proceso de implementación del FAIS suele imperar la comunicación informal y solo se recurre a la vía formal (oficios y reuniones con directivos), para "desatorar" los nudos en puestos superiores. El cuello de botella se intensifica cuando perfiles y trayectorias se mezclan y no hay un entendimiento técnico mínimo.

3. La ejecución de la obra. Una parte importante es la Dirección de Obras Públicas, que detiene o desacelera el objetivo concreto del FAIS. El problema detectado en esta parte es la falta de personal calificado, relaciones burocráticas complejas, falta de pago a los contratistas, errores frecuentes, falta de coordinación entre áreas internas e insuficiencia de vehículos para asistir a campo.

4. El desconocimiento y la poca actualización del personal en la normatividad aplicable. Algunos involucrados en el proceso no se encuentran al tanto de las principales normas y leyes aplicables a la operación del FAIS, ni de otras que se relacionan de manera indirecta, tales como la Ley de Fiscalización y Rendición de Cuentas de la Federación, lo que puede derivar en el incumplimiento involuntario de ellas.

5. La nula o deficiente construcción de indicadores. Uno de los escenarios más negativos es la ausencia de indicadores del Fondo, ya que no permite contar con un sistema institucionalizado para darle seguimiento. Los "indicadores" vigentes en el ejercicio 2015 eran los señalados en el Plan Municipal de Desarrollo 2012-2015, que presentan deficiencias serias, pues fueron construidos sin variables establecidas, ni criterios de medición específicos y un número considerable de aspectos que debe contener una herramienta de esta índole.

6. El cambio de administración. La curva de aprendizaje y la comprensión de los nuevos estilos de gestión, así como la incorporación de funcionarios a la administración pública dificulta significativamente la implementación del Fondo. 
7. La distribución de competencias y líneas de mando. El trabajo de campo permitió observar que en los gobiernos municipales imperan enfoques clásicos de la administración pública, donde la línea de mando es lo importante. Si bien las distribuciones y competencias están delimitadas y claras, lo que puede ser a la vez una fortaleza, en el caso analizado es una debilidad, porque se suelen burocratizar las actividades, debido a que dependen de una persona o área de un modo inflexible; esto, además de traducirse en rigidez, es contraproducente ante instancias externas, que terminarán señalando el incumplimiento de los objetivos del Fondo.

8. La interacción entre perfil social y técnico. Hay una división marcada entre la parte social y técnica del personal involucrado en el ejercicio del Fondo. Si bien esta situación puede ser positiva, en el caso analizado se percibe más como un divorcio. Para ilustrarlo, es posible notar que el beneficiario recibe dos tipos de acercamiento por parte del municipio: el de corte social-conciliador-humano y el técnico-rígido, cuando el escenario deseable es que los procesos se realicen con acompañamiento de ambas partes.

9. Las dificultades de comunicación con los beneficiarios y los mecanismos de seguimiento. La deficiencia se encuentra en que los implementadores no cuentan con mecanismos para expresar resultados intangibles o no deseados en términos positivos de la obra. Con esto la entrega-recepción y finiquito deja la parte contable y material para que la política pública sea multidimensional.

\section{Conclusiones}

Un enfoque territorial de las políticas públicas lleva a sostener que lo apremiante es mejorar la situación socioeconómica y las condiciones de vida de las familias, pero también permite reconocer que para los gobiernos locales resulta casi inalcanzable responder a la exigüidad de servicios básicos, pues el recurso siempre es limitado y las demandas son inagotables. Todos los días surgen asentamientos nuevos, tanto regulares como irregulares, y la autoridad debe llevar servicios públicos a relieves de toda clase sorteando dificultades territoriales y sociales.

Por el lado positivo, el enfoque territorial en las políticas públicas lleva a dimensionar y justipreciar cómo se desarrollan los procesos en el gobierno implementador, cuando se trata de llevar infraestructura básica a sus habitantes en condiciones de pobreza extrema o de alta y muy alta marginación, lo anterior complementado con la opinión de los propios beneficiarios. Así, del cúmulo de información que fue posible recabar, a continuación se hace un recuento final de los aprendizajes obtenidos, que se suman a algunas consideraciones secundarias sobre el caso y las organizaciones.

Primero, es pertinente rescatar que dentro de la organización existe la apertura para discutir alcances y resultados, con miras a entregar mejores cuentas a la población en ejercicios venideros, además de que el FAIS es el programa mejor calificado por los entrevistados y participantes del grupo de enfoque, con 
sustento en los argumentos mencionados. Segundo, se trata de una organización cuya estructura se modificó en el año de estudio, en virtud de la alternancia partidista en el poder, situación que ocasionó incertidumbre en los procesos. Dicho de otro modo, vale recomendar que los fondos federales y otros programas transexenales y transtrienales se observan con mayor detenimiento en periodos de cambio político.

En el caso analizado, la federación y el gobierno estatal no ofrecen al municipio el acompañamiento necesario en los procesos, y si bien los colaboradores de éste último se encuentran familiarizados con la operación del Fondo, cambios recientes en su reglamentación demostraron que la actualización y la capacitación en los nuevos lineamientos no llegó a todos por igual, por lo tanto se incurrió en incumplimientos por omisión y desconocimiento. El hecho es relevante, porque si esta falla ocurre en un gobierno municipal con capacidades operativas sólidas, es probable que los problemas derivados de ella sean mayores en municipios más modestos.

Por otro lado, la comunicación interna y la relación entre las dependencias merece tratamiento especial, debido a que los canales suelen ser informales y para resolver las controversias se carece de respaldo electrónico o impreso, por lo que los canales formales aparecen cuando hay que desvanecer los nudos creados por esas discrepancias. A ello hay que añadir la concentración de perfiles y formas encontradas entre las dependencias, pues mientras a una de ellas se le atribuyen los procesos sociales y de relaciones humanas, se entiende que otras son las ejecutoras de una tarea ingenieril. El caso más notorio reside en que mientras un área emite un dictamen (social) favorable para una obra, otra lo rechaza por la vía técnica y una más realiza observaciones financieras, proceso que puede parecer natural pero no deseable, porque mientras esto ocurre la población más pobre y con mayores carencias del municipio espera un servicio elemental.

Sin más, sirvan entonces los hechos y percepciones reportadas para que otros investigadores y operadores del FAIS tomen los elementos que consideren pertinentes para valorar los aspectos positivos para replicarlos en sus territorios y, por el contrario, los negativos para evitarlos, toda vez que se ha ilustrado que San Pedro Tlaquepaque es relevante en lo académico y gubernamental, y que el Fondo merece un lugar bien ponderado dentro de la agenda pública.

\section{Referencias}

Adams, N., Cotella, G., y Nunes, R. (2011). Territorial development, cohesion and spatial planning. Knowledge and policy development in an enlarged EU. New York-London: Routledge.

Atkinson, R., y Rossignolo, C. (2008). The recreation of the European city: Governance, territory and polycentricity. Ámsterdam: Techne Press.

Arellano Ríos, A. (2017). Estudio introductorio. En A. Arellano (coord.), Políticas públicas y territorio. Diseño e implementación de programas gubernamentales en Jalisco (pp. 7-25). Guadalajara: Instituto de Investigación en Políticas 
Públicas y Gobierno, Centro Universitario de Ciencias Económico-Administrativas de la Universidad de Guadalajara-El Colegio de Jalisco.

Bracho, T. (2010). Políticas públicas basadas en evidencia. La política pública como acción informada y objeto de investigación. En M. Merino y G. Cejudo (coords.), Problemas, decisiones y soluciones. Enfoques de política pública (pp. 291-319). México: Fondo de Cultura Económica-Centro de Investigación y Docencia Económicas (CIDE).

Cejudo, G., y Gerhard, R. (2010). La rendición de cuentas de transferencias intergubernamentales: el caso del FAIS. En M. Merino, S. Ayllón y G. Cejudo, La estructura de rendición de cuentas en México (pp. 205-233). México: CIDE.

Centro de Estudios de las Finanzas Públicas (CEFP). (2007). Impacto del FAIS sobre el índice de marginación 2000-2005. En Nota informativa. México: Centro de Estudios de las Finanzas Públicas-Cámara de Diputados, 23 de julio.

Consejo Nacional de Evaluación (CONEVAL). (2010). Informe anual sobre la situación de pobreza y rezago social. Recuperado de https://www.gob.mx/cms/ uploads/attachment/file/43127/Jalisco_098.pdf

Giménez, G. (2012). El problema de la generalización en los estudios de caso. Cultura y Representaciones Sociales, 7(13), 40-62.

Hernández Trillo, F., y Jarillo, B. (2007). Transferencias condicionadas federales en países en desarrollo: el caso del FISM en México. Estudios Económicos, 22(2), 143-184.

Instituto Nacional de Estadística y Geografía (INEGI). (2015). Encuesta Intercensal. Panorama sociodemográfico de Jalisco 2015. http: / / internet.contenidos. inegi.org.mx/contenidos/Productos/prod_serv/contenidos/espanol/bvinegi / productos/nueva_estruc/inter_censal/panorama/702825082239.pdf

Mendoza, X., y Vernis, A. (2008). The changing role of governments and the emergence of the relational state. Corporate Governance, 8(4), 389-396.

Merino, M. (2013). Políticas públicas. Ensayo sobre la intervención del Estado en la solución de problemas públicos. México: CIDE.

Muller, P. (2000). Las políticas públicas entre sectores y territorios. INNOVAR: Revista de Ciencias Administrativas, (16), 55-64.

Muller, P. (2009). Las políticas públicas. Bogotá: Universidad Externado de Colombia.

Ramones, F., y Prudencio, D. (2014). Los efectos del Fondo de Aportaciones para la Infraestructura Social sobre la pobreza en México. región y sociedad, 26(60), 63-88. doi: 10.22198/rys.2014.60.a9

Vázquez Elorza, A. , y Reyes, A. (2016). Política pública en materia de desarrollo social mediante el Fondo de Infraestructura Social Municipal Potosino. EconoQuantum, 13(1), 29-49.

Vernis Domènech, A., y Mendoza Mayordomo, X. (2009). Una aproximación a la conceptualización del nuevo rol del Estado: el Estado relacional. Revista del CLAD Reforma y Democracia, (44), 115-144.

Wellenstein, A., Núñez, A., y Andrés, L. (2006). Social infrastructure: Fondo de Aportaciones para la Infraestructura Social (FAIS). En The World Bank, Decentralized Service Delivery for the Poor (pp. 167-222). Washington: The World Bank. Recuperado de http://documents.worldbank.org/curated/ en/276851468052769363/pdf/356920v20ENGLI1MENTOFILE01Same0Box1.pdf 